\title{
Role of Microorganisms in the Degradation of Organic Pollutants: A Review
}

\author{
Mbachu A. E. ${ }^{1, *}$, Chukwura E. I. ${ }^{1}$, Mbachu N. A. ${ }^{2}$ \\ ${ }^{1}$ Department of Applied Microbiology \& Brewing, Faculty of Biosciences, Nnamdi Azikiwe University, Nigeria \\ ${ }^{2}$ Department of Human Biochemistry, Faculty of Basic Medical Sciences, Nnamdi Azikiwe University, Nigeria
}

Received January 10, 2020; Revised February 20, 2020; Accepted February 24, 2020

Copyright $\bigcirc 2020$ by authors, all rights reserved. Authors agree that this article remains permanently open access under the terms of the Creative Commons Attribution License 4.0 International License

\begin{abstract}
Environmental pollution by organic waste especially hydrocarbons, pesticides, herbicides and other toxic wastes is a global problem. The petroleum industry has created economic boom for many countries and at the same time led to environmental and socio-economic problems. Release of hydrocarbons into the environment whether accidental or due to human activities is the main cause of water and soil pollution. Pesticide application on agricultural soil is now a common practice. Some of these pesticides persist in the soil to form pollutants which may occasionally lead to surface and ground water contamination. It is an important subject to study the role of microorganisms in organic pollutant biodegradation as it is a safe alternative to physicochemical techniques. This paper summarized the general principles of organic pollutant degradation by microorganisms. Emphasis was laid on the biochemistry of hydrocarbon oxidation viz; terminal and sub terminal oxidation of n-alkanes as well as anaerobic degradation of alkanes. This paper also highlighted the pathways for the biodegradation of organic chemicals such as pesticides as well as factors affecting organic pollutant biodegradation. Beside these factors affecting biodegradation, efforts at improving the biodegradative capabilities of microorganisms through biostimulation, bioaugmentation and the use of genetically engineered microorganisms (GEM) were also discussed.
\end{abstract}

Keywords Hydrocarbons, Pesticides, Alkane Oxidation, Biostimulation, Bioaugmentation, Organic Pollutants

\section{Introduction}

Environmental pollution by organic compounds of anthropogenic origin is a major global problem. Common organic pollutants of public health concern include petroleum hydrocarbons, from petroleum industry, many insecticides and herbicides that have been used in agriculture and pest control. Other organic pollutants are by-products of manufacturing industries. For example, phthalates are plasticizers used in bottles, toys and personal care products. Polybromated diphenyl esters (PBDEs) are fire retardants added to a large variety of consumer items, that leach into surrounding materials and can now be detected in many populations [1].

Release of hydrocarbons into the environment whether accidental or due to human activities is the main cause of water and soil pollution [2]. Petroleum hydrocarbon pollutants are known to have adverse effects on aquatic and terrestrial life [3] as well as soil productivity. The intensive use of pesticides, antibiotics, non-steroidal anti-inflammatory drugs (NSAIDs) and other chemicals, their disposal and consequent presence in various environments, are of great concern due to their ecotoxicological effects on different organisms. Such widespread use results in an increased concentration of these compounds in water, sediments and soil. The increasing awareness of the risks to humans related to organic pollutants has led to the development of effective strategies to detoxify or clean up these pollutants.

Microbial degradation or biodegradation is the use of microorganisms to breakdown or degrade, detoxify or transform environmental pollutants. Biological decomposition of various substrates is performed by a large number of microorganisms [4] including bacteria, fungi, protozoa, etc. Organic pollutants may undergo different changes once they enter the environment, including transformation or degradation, sorption-desorption, volatilization, uptake by plants, run off into surface waters and transport into groundwater. Transformation or degradation is one of the key processes that governs environmental fate and transport of organic pollutants, which also comprises different processes including abiotic degradation and biodegradation. During these processes, organic pollutants are transformed into the degradation products or are completely mineralized to a carbon field. Although abiotic degradation plays a role 
in many cases, the biodegradation of pollutants by microorganisms is usually the most important and dominant process due to its environmental friendliness and the ability of microorganisms to adapt to changing environmental conditions, their non specific enzymes also makes them versatile in degrading pollutants. Interest in the microbial degradation of pollutants has intensified $[5,6]$, due to recent breakthroughs which has enabled detailed genomic, metagenomic, bioinformatic and other high-throughput analysis of environmentally relevant microorganisms. This provides new insights into their biodegradative mechanisms and metabolic pathways.

\section{Principle of Microbial Degradation of Organic Pollutants}

Organic pollutant degradation by microorganisms can occur under both aerobic and anaerobic conditions. However, the most rapid and complete biodegradation of the majority of organic pollutants takes place under aerobic conditions [2]. "The initial intracellular attack of organic pollutant for example hydrocarbon is an oxidative process and the activation as well as incorporation of oxygen is the enzymatic key reaction catalyzed by oxygenases and peroxidases. Peripheral degradation pathways convert organic pollutants step by step into intermediates of the central intermediary metabolism, for example, the tricarboxylic acid cycle. Biosynthesis of cell biomass occurs from the central precursor metabolites, for example, acetyl-CoA, succinate, pyruvate. Sugars required for various biosynthesis and growth are synthesized by gluconeogenesis" [2]. Figure 1 shows the main principle of aerobic degradation of hydrocarbons.

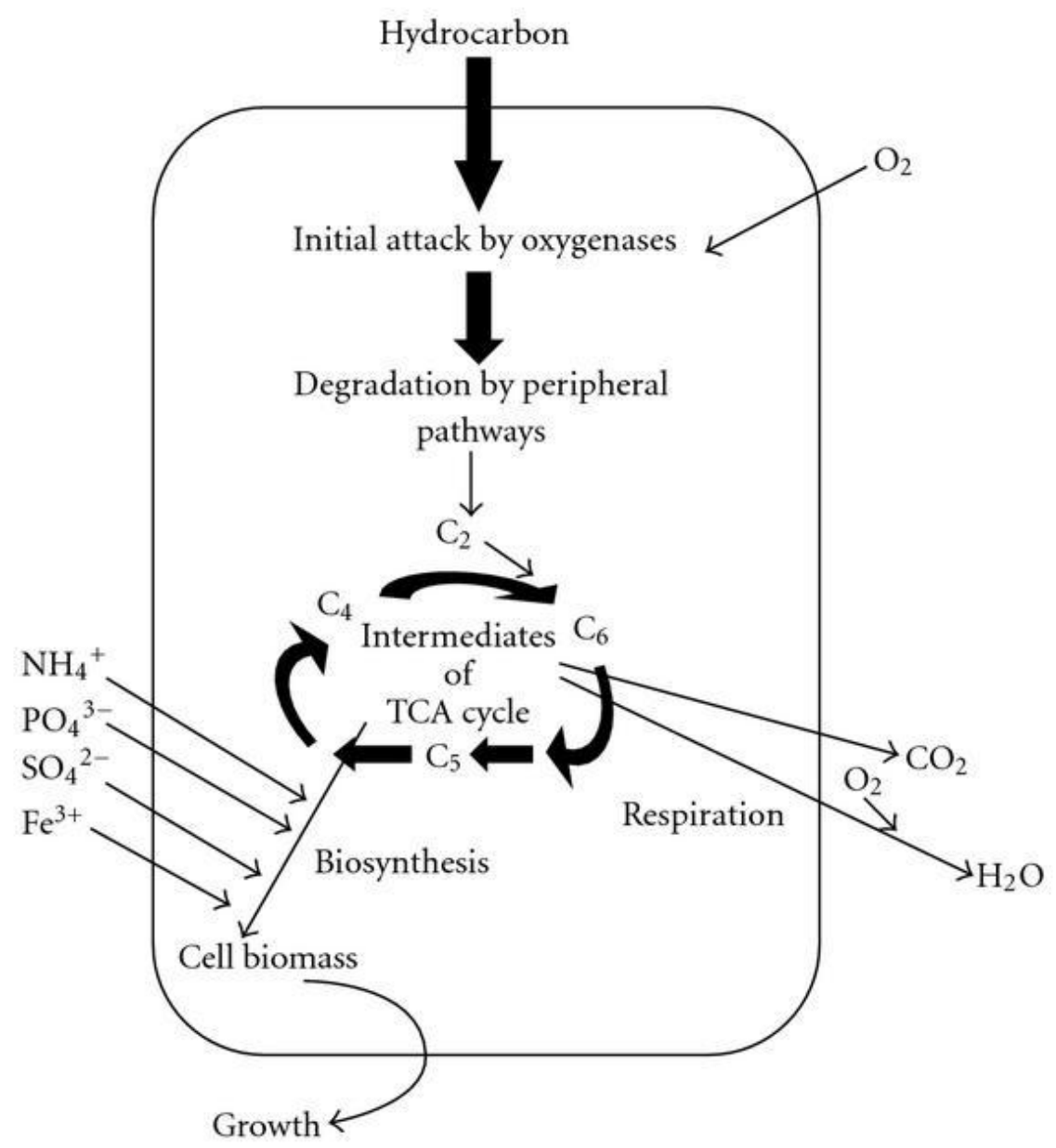

Figure 1. Main principle of aerobic degradation of hydrocarbons by microorganisms [2] 


\section{Biodegradation of Petroleum Hydrocarbons}

Biodegradation of petroleum hydrocarbons is a complex process that depends on the nature and the amount of the hydrocarbon present, as well as the chemical composition of the petroleum hydrocarbons [2]. Susceptibility of a hydrocarbon to microbial degradation varies with type and size of the hydrocarbon molecule. Short chain alkanes $\left(<\mathrm{C}_{10}\right)$ are solvents and as solvents, they tend to disrupt the lipid membrane structures of microorganisms [7], this makes them toxic to many microorganisms. They are primarily removed by volatilization. Alkanes of intermediate chain length $\left(\mathrm{C}_{10}-\right.$ $\mathrm{C}_{24}$ ) are often degraded rapidly, while very long chain alkanes are increasingly resistant to microbial biodegradation [8,9]. Hydrocarbons differ in their susceptibility to microbial attack and ranked in the following order of decreasing susceptibility: n-alkanes $>$ branched alkanes $>$ low molecular weight aromatics $>$ cyclic alkanes [10].

It has been established that the first step in the aerobic degradation of hydrocarbons by bacteria is usually the introduction of molecular oxygen in the hydrocarbon. Prokaryotes convert aromatic hydrocarbons by an initial dioxygenase attack to trans-dihydrodiols that are further oxidized to dihydroxy products, example catechol in the case of benzene [7]. Eukaryotic microorganism use mono-oxygenases, producing benzene 1,2-oxide from benzene, followed by the addition of water, yielding dihydroxydihydrobenzene (Cis-dihydrodiol). This is oxidized in turn to catechol, a key intermediate in biodegradation of aromatic, which is then opened by ortho or meta cleavage, yielding muconic acid or hydroxymuconic semialdehyde, respectively [10].

\section{Biochemistry of Hydrocarbon Oxidation}

\subsection{Microbial Alkane Oxidation}

Alkanes (whether short or long chains) undergo terminal (monoterminal) oxidation to the corresponding alcohols, aldehydes and monobasic fatty acids, followed by beta oxidation. However, further observation suggests diterminal and subterminal n-alkane or fatty acid oxidation that is frequently found in branched alkanes $[11,12]$. The enzymology of alkane oxidation is not clear yet, however, common accepted mechanisms are dehydrogenation, hydroxylation, and hydroperoxidation [12]. N-alkanes are the most easily degradable components of petroleum, followed by cycloalkanes; while the aromatic fraction is the most resistant to microbial attack.

\subsubsection{Terminal Oxidation of n-Alkanes}

Initiation of attack on alkanes occurs through the incorporation of molecular oxygen into the alkane molecule, by an oxygen-dependent enzyme called oxygenases. In the case of n-alkanes containing two or more carbon atoms, aerobic degradation usually starts by the oxidation of a terminal methyl group to yield a primary alcohol [13]. This is in turn oxidized further to the corresponding aldehyde and finally converted into a fatty acid (Fig. 2). Fatty acids are activated and further processed by $\beta$-oxidation sequence to generate acetyl-CoA. In some cases, both ends of the alkane molecule are oxidized through di-terminal or $\omega$-hydroxylation of fatty acids to render a $\omega$-hydroxy fatty acid that is further converted into a dicarboxylic acid and processed by $\beta$-oxidation sequence $[13,14]$, which results in the formation of acetyl CoA. The acetyl CoA enters the tricarboxylic acid (TCA) cycle where it will be mineralized to carbondioxide $\left(\mathrm{CO}_{2}\right)$ and water $\left(\mathrm{H}_{2} \mathrm{O}\right)$.

\subsubsection{Subterminal Oxidation of n-Alkane}

Subterminal oxidation of n-alkanes has also been reported $[15,16]$. The product generated a secondary alcohol, is converted to the corresponding ketone and then oxidized by a Baeyer-Villiger Monoxygenase to produce an ester. The ester is hydrolyzed by an esterase, generating an alcohol and a fatty acid, which enters the $\beta$ oxidation sequence (Fig. 3). Both terminal and subterminal oxidation can coexist in some microorganisms [13]. 


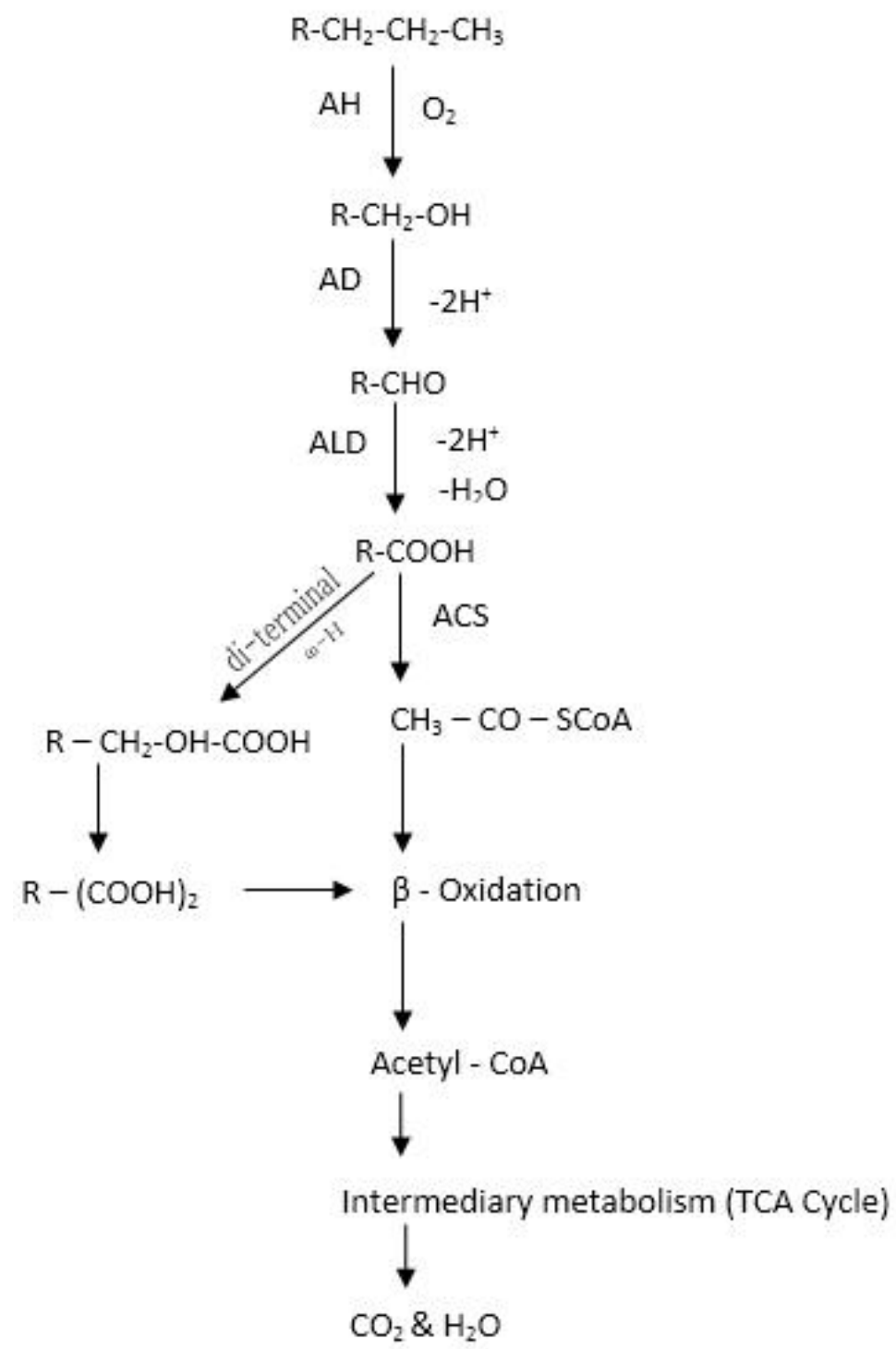

Figure 2. Pathway for the terminal oxidation of alkane. AH, alkane hydroxylase; AD, alcohol dehydrogenase; ALD, aldehyde dehydrogenase; ACS, acyl - CoA synthetase; $\omega-\mathrm{H}, \omega$-hydroxylase 


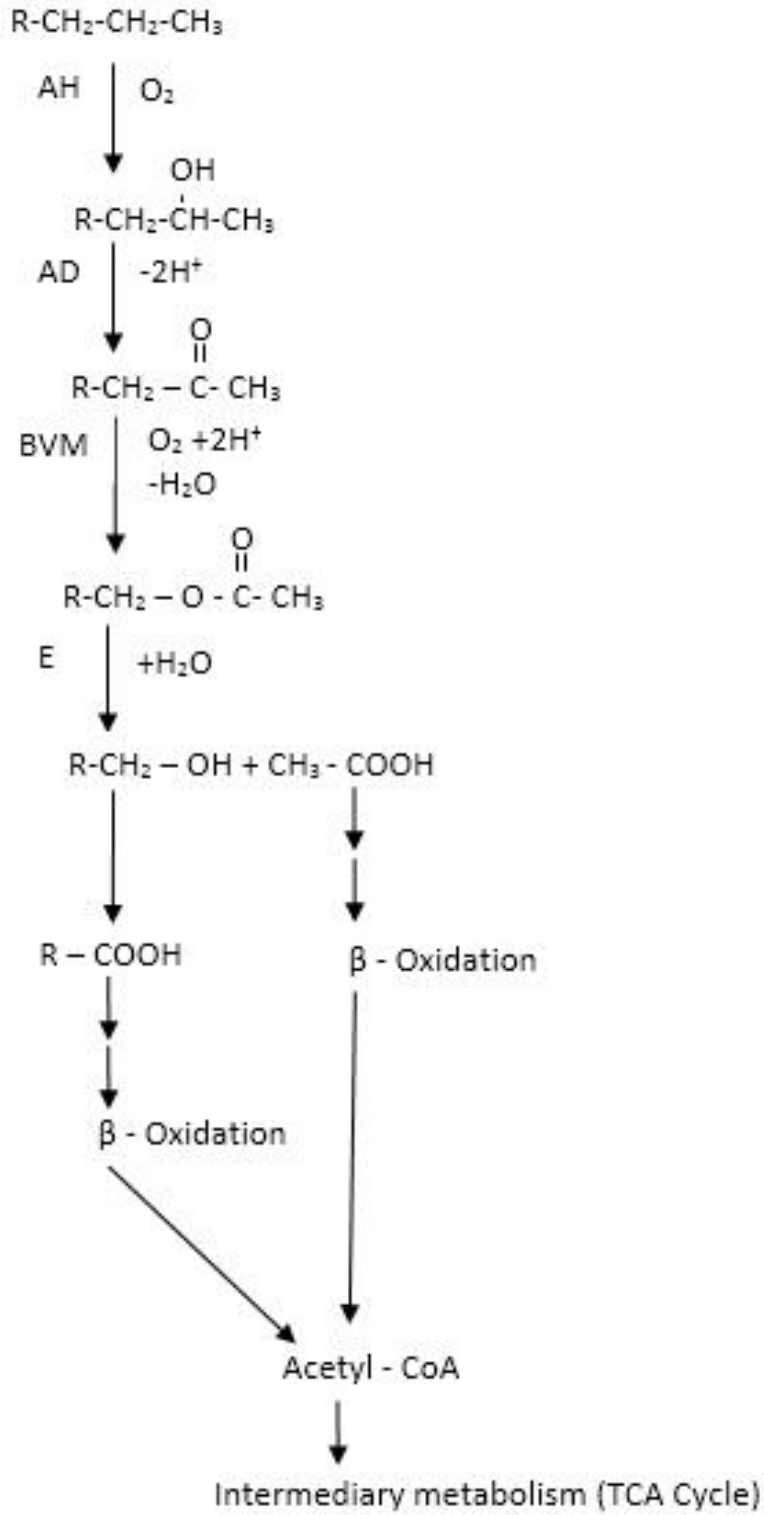

Figure 3. Pathway for the subterminal oxidation of $n$ - alkane. BVM, Baeyer villager monoxygenase; E, esterase

\subsection{Anaerobic Degradation of Alkanes}

In the subsurface, oil biodegradation occurs primarily under anoxic conditions, mediated by sulfate reducing bacteria [7] or other anaerobes using a variety of other electron acceptors as an oxidant. Hydrocarbon biodegradation under anaerobic, denitrifying conditions also follows an oxidative strategy. In the presence of nitrate hydrocarbon substrates e.g., toluene, are metabolized to oxidized intermediates prior to further biodegradation [10]. Anaerobic microbial degradation of petroleum hydrocarbons in natural environments has been shown to occur only at negligible rates and its ecological significance has been generally considered to be minor [10]. However, the microbial degradation of oxidized aromatic compounds such as benzoate and halogenated aromatic compounds such as the halobenzoates, chlorophenols and polychlorinated biphenyls has been shown to occur under anaerobic conditions [10].

Many bacterial strains able to use alkanes as carbon sources in anoxic environments have been described [13]. These microorganisms use nitrate or sulfate as electron acceptor. Growth is significantly slower than that of aerobic alkane degraders. However, anaerobic degradation of alkanes also plays an important role in the recycling of hydrocarbons in the environment. For examples, Strain Bus5, a sulfate reducing bacteria that belongs to the genera Desulfosarcina/Desulfococcus cluster, assimilates only propane and butane [17,13]; Azoarcus sp. HxNI, a denitrifying bacteria, uses $\mathrm{C}_{6}-\mathrm{C}_{8}$ alkanes, while Desulfobacterium $\mathrm{HdX} 3$ metabolizes $\mathrm{C}_{12}-\mathrm{C}_{20}$ alkanes [13] 


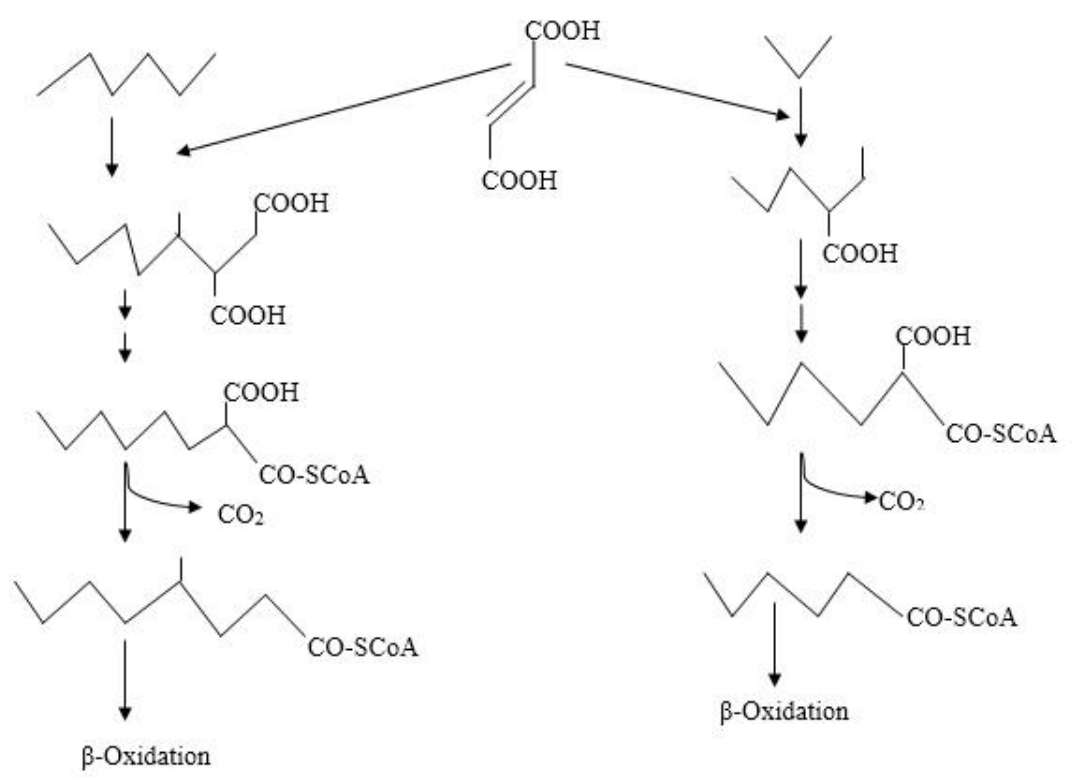

Figure 4. Anaerobic degradation of alkanes by addition of fumarate molecule [13]

\subsubsection{Pathways for Anaerobic Degradation of Alkanes}

The metabolic pathways for anaerobic degradation of alkanes have been investigated for some strains [13]. Two general strategies appear to be used (Fig. 4). One involves activation of the alkane at a subterminal position by addition of a fumarate molecule to the alkane, yielding an alkyl-succinate derivative. This reaction is believed to occur through generation of an organic radical intermediate, most likely a glycyl radical [18,13]. The reaction product is subsequently, linked to $\mathrm{CoA}$ and converted into an acyl-CoA that can be further metabolized by $\beta$-oxidation. In the second reaction mechanism, which has been described only for propane (Fig.4), the fumarate molecule is added to one of the terminal carbon atoms of the alkane $[17,13]$.

\section{Biodegradation of Organic Chemicals (Pesticides)}

Pesticides are organic chemicals used to increase agricultural yield by minimizing losses of agricultural products through preventing, destroying, repelling or mitigating any pest. The term pesticide also applies to herbicides, fungicides and various other substances used to control pests. Pesticide application on agricultural soil is now a common practice and is an important factor of integrated pest management (IPM) strategies [19,20]. Some of these pesticides persist in the soil to form pollutants which may occasionally lead to surface and ground water contamination [20]. The bacteria and fungi are the major organisms involved in pesticide degradation.

There are various sources of microorganisms with pesticide degrading potentials. Generally, microorganisms that have been identified as pesticide degraders have been isolated from a wide variety of pesticide contaminated sites. The soil is the medium that mostly get these chemicals, when they are applied to agricultural crops. However, the pesticide industry's effluent, sewage sludge, activated sludge, wastewater, natural waters, sediments, areas surrounding the pesticide industries are also rich sources of pesticide degrading microorganisms [21]. Abo-Amer [22] reported that Pseudomonas, sp. is the most efficient bacterial genus for the degradation of toxic compounds. The isolation of various fungi species such as Aspergillus fumigatus, A. niger, A. terreus, Absidia and Rhizopus microsporus var corymberifera microsporis from Algerian pesticide contaminated soils was reported [23]. Moreover, the fungi Trichoderma viridae have been implicated in the endosulfan and methyl parathion pesticides degradation [24].

The intracellular or extracellular enzymes of these microorganisms play a major role in the degradation of these organic pollutants. However, the absence of microbial systems that have the pesticide degrading enzymes, lead to the persistence of these chemicals in the soil. In such cases, the external addition of pesticide degrading microflora is recommended [25]. Moreover, the biotransformation of such chemical pollutants depends not only on the presence of microorganisms with appropriate degrading enzymes, but on a wide range of environmental paremeters [21] such as temperature, $\mathrm{pH}$, redox potentials, nutrients, contact time, water activity, etc. However, some other aspects such as physiological, ecological, biochemical and molecular, play important roles in the microbial transformation of pollutants $[26,27,22]$.

\subsection{Mechanism of Microbial Degradation of Pesticides}

Microbial degradation of pesticides may involve a 
three-phase process. "In Phase I, the initial properties of a parent compound are transformed through oxidation, reduction, or hydrolysis to produce a more water-soluble and usually a less toxic product than the parent compound. The second phase involves conjugation of a pesticide or pesticide metabolite to a sugar or amino acid, which increases the water solubility and reduces toxicity compared with the parent pesticide. The third phase involves conversion of Phase II metabolites into secondary conjugates, which are also non-toxic. In these processes, fungi and bacteria are involved producing intracellular or extra cellular enzymes including hydrolytic enzymes, peroxidases, oxygenases, etc" [23].

\subsubsection{Mineralization}

Mineralization was a general term for the conversion of organic compounds into inorganic compounds under the action of soil microbes [28]. Many pesticides were analogs of natural compounds, and some microorganism had the enzymes to degrade them. They could be used as a source of microbial nutrients and then be degraded to inorganic matters, carbon dioxide, and water by microorganism. Mineralization was an ideal way to degrade because pesticides were completely degraded into non-toxic inorganic substance. Co-metabolism played a major role in the microbial degradation of pesticides. It should be noted that in most cases, the synergistic effect of a series of reactions rather than a single reaction was needed to complete the degradable process of pesticides in the microbial body. For example, Deng et al. [29] found that Aspergillus niger YAT could degrade beta-CY $(\beta-\mathrm{CY})$ and its intermediates completely by co-metabolism and mineralization. The pathway of $\beta-\mathrm{CY}$ degradation by Aspergillus niger YAT is shown in Figure 5.

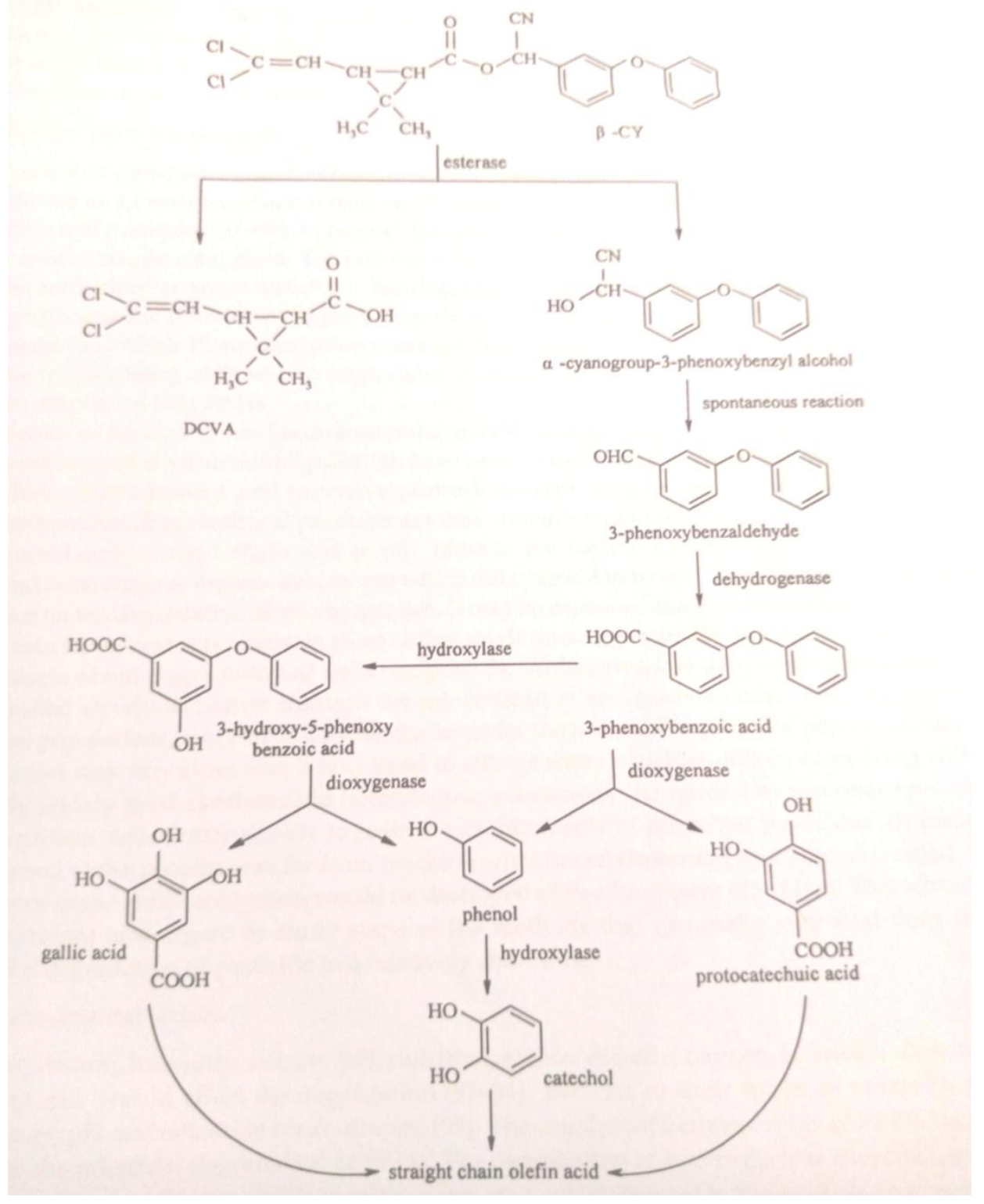

Figure 5. Degradation pathway of beta-CY by Aspergillus niger YAT [28,29]. 


\section{Factors Affecting Organic Pollutant Biodegradation}

Microorganisms can degrade a wide range of organic pollutants owing to their nonspecific metabolic machinery and to their capacity to adapt to adverse environmental conditions. Thus, microorganisms are major players in site remediation. However, their efficiency depends on many factors, including the chemical nature and the concentration of pollutants, their availability to microorganisms (bioavailability), and the physicochemical characteristics of the environment [30]. It is important to understand the factors limiting biodegradation of organic pollutants in order to adopt appropriate methodologies to optimize the process. Major environmental factors which influence microbial degradation of organic pollutants are summarized below.

\subsection{Nutrients}

Sufficient amounts of nutrients and oxygen must be available in a usable form and in proper proportions for unrestricted microbial growth to occur [31]. Many bacteria and fungi require low concentrations of one or more amino acids and vitamins. Nitrogen and phosphorus are also necessary for cellular metabolism.

\subsection{Temperature}

Biological enzymes involved in the degradation pathway have an optimum temperature and will not have the same metabolic turnover for every temperature [32]. Indeed, the rate of biodegradation is decreased by roughly one-half for each $10^{\circ} \mathrm{C}$ decrease in temperature [30].

\section{3. $\mathrm{pH}$}

Biodegradation can occur under a wide-range of $\mathrm{pH}$; however, a $\mathrm{pH}$ of 6.5 to 8.5 is generally optimal for biodegradation in most aquatic and terrestrial systems. Moreover, most heterotrophic bacteria favour a $\mathrm{pH}$ of 7.0 but fungi are more tolerant to acidic conditions.

\subsection{Moisture}

Moisture influences the rate of contaminant metabolism because it influences the kind and amount of soluble materials that are available as well as the osmotic pressure and $\mathrm{pH}$ of terrestrial and aquatic systems [33].

\subsection{Oxygen}

Oxygen is another important parameter because it determines the microbial pattern of dissimilation and energy yielding process. Utilization of organic pollutants for example, hydrocarbons by bacteria and fungi require electron sink. In the initial attack, molecular oxygen is used as electron sink. In the subsequent steps too, oxygen is the most common electron sink. In the absence of molecular oxygen, further biodegradation of partially oxygenated intermediates may be supported by nitrate or sulphate reduction [10].

\subsection{Soil Type}

Soil type and soil organic matter content affects the potential for adsorption of an organic compound to the surface of a solid. Absorption is an analogous process wherein a contaminant penetrates into the bulk mass of the soil matrix. Both adsorption and absorption reduce the availability of the contaminant to most microorganisms and the rate at which the chemical is metabolized is proportionately reduced [30]. Variations in porosity of the unsaturated and saturated zones of the aquifer matrix may influence the movement of fluids and contaminant migration in groundwater. The ability of the matrix to transmit gases, such as oxygen, methane and carbon dioxide, is reduced in fine grained sediments and also when soils become more saturated with water. This can affect the rate and type of biodegradation taking place [31].

\subsection{Oxidation-Reduction Potential}

The oxidation-reduction potential of a soil provides a measurement of the electron density of the system. Biological energy is obtained from the oxidation of compounds in which electrons are transferred to various more oxidized compounds referred to as electron acceptors. A low electron density (Eh greater than $50 \mathrm{mV}$ ) indicates oxidizing, aerobic conditions, whereas high electron density (Eh less than $50 \mathrm{mV}$ ) indicates reducing, anaerobic conditions [30].

\section{Improving the Biodegradative Capabilities of Microorganisms}

Biodegradative capabilities of microorganism could be enhanced either by biostimulation, bioaugmentation or by use of genetically engineered microorganisms (GEMs).

\subsection{Biostimulation}

Biostimulation is the addition of nutrients, trace minerals, electron acceptors, or electron donors to enhance the biotransformation of a wide range of soil contaminants [34] by indigenous microorganisms. Biostimulation aims at enhancing the activities of indigenous microorganisms that are capable of degrading pollutants from the soil environment. Trichloroethene and perchloroethene are reported to be completely converted 
to ethane by microorganisms in a short span of time with the addition of lactate during biostimulation [35]. The biostimulation of indigenous microorganisms by the addition of lactate and anthraquinone-2,6-disulfonate (AQDS) led to the enhanced rates of pentachlorophenol (PCP) dechlorination by the dechlorinating and iron reducing bacteria in soils [36]. Chen et al. [37] reported that among various nutrient media, glycerol appeared to show the most favorable metabolic characteristics against phenol toxicity on the indigenous Rhizobium Ralstonia taiwanensis, leading to better degradation efficiency of the toxic pollutant. Liliane et al. [38] observed that biostimulation was more efficient when compared to natural attenuation of biodiesel in contaminated soils. Frederic et al. [39] observed that addition of commercial oleophilic fertilizers containing nitrogen and phosphorus to hydrocarbon contaminated soil increased the hydrocarbon-degradation microbial abundance and total petroleum hydrocarbon degradation. In another study using poultry manure as organic fertilizer in contaminated soil, biodegradation was reported to be enhanced in the presence of poultry manure alone, but the extent of biodegradation was influenced by the incorporation of alternate carbon substrates of surfactants [40]. However, excessive nutrient concentrations can inhibit the biodegradation activity [41].

\subsection{Bioaugmentation}

Bioaugmentation is an approach that involves introduction of microorganisms that possessed biodegradation potentials into the contaminated environment to assist the indigenous microorganisms with biodegradative processes [42]. This may sometimes involve the addition of genetically engineered microorganisms (GEMs) suited for biodegradation of the hydrocarbon contaminants into the contaminated soil. Bioaugmentation offers a way to provide specific microbes in sufficient number to complete the biodegradation process. Over the years, contaminating compounds as insecticides, petroleum compounds and a growing number of toxic organic chemicals have been successfully remediated using bioaugmentation [43,44]. It is thought that bioaugmentation approach should be applied when the biostimulation and bioattenuation have failed [30]. Many studies have shown that both abiotic and biotic factors influence the effectiveness of bioaugmentation, the most important abiotic factors are temperature, moisture, $\mathrm{pH}$ and organic matter content, however, aeration, nutrient content and soil type also determine the efficiency of bioaugmentation. Biotic factors, including competition between indigenous and exogenous microorganisms for limited carbon sources as well as antagonistic interactions and predation by protozoa and bacteriophages, also play essential roles in the final results of bioaugmentation [45]. The combination of bioaugmentation and biostimulation may be a promising strategy to speed up bioremediation. Both indigenous and exogenous microorganisms could benefit from biostimulation by the addition of energy sources or electron acceptors [30].

\subsection{Genetically Engineered Microorganisms}

Genetically engineered microorganisms are those microorganisms whose genetic makeup has been altered by applying genetic engineering techniques inspired by natural or artificial genetic exchange between microorganisms [46]. Genetic engineering has improved the utilization and elimination of hazardous wastes under laboratory conditions by creating genetically modified organisms [10]. GEMs have shown potential for biodegradative applications in soil, groundwater and activated sludge environments, exhibiting enhanced degradative capabilities encompassing a wide range of chemical pollutants [46]. Genes responsible for degradation of environmental pollutants, for example, toluene, chlorobenzene acids, and other halogenated pesticides and toxic wastes have been identified and grouped into four categories: 1) OCT plasmid which degrades, octane, hexane and decane; 2) XYL plasmid which degrades xylene and toluenes, 3) CAM plasmid that decompose camphor and 4) NAH plasmid which degrades naphthalene [30]. Pseudomonas putida that contained the $\mathrm{XYL}$ and NAH plasmid as well as a hybrid plasmid derived by recombinating parts of CAM and OCT developed by conjugation could degrade camphor, octane, salicylate, and naphthalene [47] and could grew rapidly on crude oil because it was capable of metabolizing hydrocarbons more efficiently than any other single plasmid [48]. This product of genetic engineering was called a superbug (oil eating bug) [30]. Molecular techniques, either through plasmid breeding or genetic engineering, could rapidly produce microorganisms with higher catalytic abilities, able to degrade any environmental pollutant [47]. The use of GEM strains as an inoculum during seeding would preclude the problems associated with competition between strains in a mixed culture. However, there is considerable controversy surrounding the release of such genetically engineered microorganisms into the environment, and field testing of these organisms must therefore be delayed until the issues of safety and the potential for ecological damage are resolved [49].

\section{Conclusions}

The use of microorganisms in organic pollutant biodegradation is a natural way of mitigating waste; thus, attractive and generally acceptable. Biodegradation produces as end products innocuous substances including 
microbial biomass, carbon dioxide and water, which are all environmentally friendly. Bioaugmentation, biostimulation or GEMs could be used to accelerate the recovery of polluted sites. However, selection of microorganisms with the appropriate enzymes involved in the biodegradative processes is encouraged. Suitable environmental conditions should be maintained during biodegradative studies. Moreover, the increasing amount of bacterial genomic data provides new opportunities for understanding the genetic and molecular bases of the degradation of organic pollutants.

\section{REFERENCES}

[1] Schell, L.M., Knutson, K.L. and Bailey, S. Environmental effects on growth. Human growth and development (2nd edn.) Elsevier, 2012: 245-286.https://doi.org/10.1016/B978-0-12-383882-7.000 10-6.

[2] Das, N. and Chandran, P. Microbial degradation of petroleum hydrocarbon contaminants: An overview. Biotechnology Research International, 2011: 1-13. Doi:10.4061/2011/941810.

[3] Saadoun, M.K. Impact of oil spills on marine life, emerging pollutants in the environment - current and further implications, Marcelo L. Larramendy and Sonia Soloneski (edn.), IntechOpen, 2015. DOI: 10.5772/60455. Available from:

https://www.intechopen.com/books/emerging-pollutants-in -the-environment-current-and-further-implications/impactof-oil-spills-on-marine-life.

[4] Rozalska, S. and Iwanicka-Nowicka, R. Organic pollutants degradation by microorganisms. Genomics, Metagenomics and Metatranstriptomics: Backgrounds. Microbial biodegradation, from omics to function and application. Jerzy Dlugonski (edn.) Caister Academic Press, 2016: $1-12$.

[5] Diaz, E. Microbial Biodegradation: Genomics and Molecular Biology. (1st edn.), Caister Academic Press, UK., 2008: 402.

[6] Koukkou, A. Microbial bioremediation of non-metals: Current Research. Caister Academic Press, UK. 2011.

[7] Okoh, A.I. Biodegradation alternative in the cleanup of petroleum hydrocarbon pollutants. Biotechnology and Molecular Biology Reviews, 2006; 1: 38-50.

[8] Bagherzadeh-Namazi, A., Shojaosadati, S.A. and Hashemi-Najafabadi, S. Biodegradation of used engine oil using mixed and isolated cultures. International Journal of Environmental Research, 2008; 2(4): 431-440.

[9] Mbachu, A.E., Mbachu, N.A. and Chukwura, E.I. Biodegradation of $n$-alkanes by fungi isolated from waste engine oil polluted soil and their extracellular enzyme activities. International Journal of Novel Research in Life Sciences, 2016; 3(4): 7-17.

[10] Jain, P.K., Gupta, V.K., Gaur, R.K., Lowry, M., Jaroli, D.P. and Chauhan, U.K. Bioremediation of Petroleum Oil Contaminated Soil and Water. Research Journal of Environmental Toxicology, 2011; 5: 1-26.

[11] Cong, L.T.N., Mikolasch, A., Awe, S., Sheikhany, H. and Klent, H.P. Oxidation of aliphatic, branched chain and aromatic hydrocarbons by Nocardia cyriacigeorgica isolated from oil-polluted sand samples collected in the Saudi Arabian Desert. Journal of Basic Microbiology, 2010; 50: 241-253.

[12] Shukla, A. and Cameotra, S.S. Hydrocarbon pollution: Effects on living organisms, remediation of contaminated environments and effects of heavy metals co-contamination on bioremediation. Laura Romero-Zeron (Ed.), InTech, China, 2012: 185-206.

[13] Rojo, F. Degradation of alkanes by bacteria. Environmental Microbiology, 2009; 11:2477-2490. Doi: 10.1111/j.1462-2920.2009.01948.x

[14] Coon, M.J. Omega oxygenases: nonheme-iron enzymes and P450 cytochrome. Biochemical and Biophysical Research Communications, 2005; 338: 378-385.

[15] Kotani, T., Kawashima, Y., Yurimoto, H., Kato, N. and Sakai, Y. Gene structure and regulation of alkane monooxygenases in propane-utilizing Mycobacterium sp. TY-6 and Pseudonocardia sp. TY-7. Journal of Bioscience and Bioengineering, 2006; 102: 184-192.

[16] Kotani, T., Yurimoto, H., Kato, N. and Sakai, Y. Novel acetone metabolism in a propane-utilizing bacterium, Gordonia sp. strain TY-5. Journal of Bacteriology, 2007; 189: 886-893.

[17] Kniemeyer, O., Musat, F., Sievert, S.M. et al. Anaerobic oxidation of short chain hydrocarbons by marine sulphate-reducing bacteria. Nature, 2007; 449: 898 - 901.

[18] Rabus, R., Wilkes, H., Behrends, A. et al. Anaerobic initial reaction of n-alkanes in a denitrifying bacterium: evidence for (1-methylpentyl) succinate as initial product and for involvement of an organic radical in n-hexane metabolism. Journal of Bacteriology, 2001; 183: 1707-1715.

[19] Gilani, S.T.S.; Ageen, M.; Shah. H. and Raza, S. Chlorpyrifos degradation in soil and its effect on soil microorganisms. Journal of Animal and Plant Sciences, 2010; 20(2): 99-102.

[20] Ifediegwu, M.C., Agu, K.C., Awah, N.S., Mbachu, A.E., Okeke, C.B., Anaukwu, C.G., Uba, P.O., Ngenegbo, U.C. and Nwankwo, C.M. Isolation, growth and identification of chlorpyrifos degrading bacteria from agricultural soil in Anambra State, Nigeria. Universal Journal of Microbiology Research, 2015; 3(4): 46-52. Doi:10.13189/ujmr.2015.030402.

[21] Parte, S.G., Mohekar, A.D. and Kharat, A.S. Microbial degradation of pesticide: a review. African Journal of Microbiology Research, 2017; 11(24): 992-1012. Doi: 10.5897/AJMR2016.8402.

[22] Abo-Amer, A.E. Characterization of a strain of Pseudomonas putida isolated from agricultural soil that degrades cadusafos (an organophosphorus pesticide). World Journal of Microbiology and Biotechnology, 2012; 28: 805-814.

[23] Ortiz-Hernández, M.L., Sánchez-Salinas, E., 
Dantán-González, E. and Castrejón-Godínez, M.L. Pesticide biodegradation: Mechanisms, genetics and strategies to enhance the process. IntechOpen Chapter 10 , 2013. http://dx.doi.org/10.5772/56098.

[24] Senthilkumar, S., Anthonisamy, A., Arunkumar, S. and Sivakumari, V. Biodegradation of methyl parathion and endosulfan using Pseudomonas aeruginosa and Trichoderma viridae. Journal of Environtal Science and Engineering, 2011; 53(1): 115-122.

[25] Singh, D.K. Biodegradation and bioremediation of pesticide in soil: concept, method and recent developments. Indian Journal of Microbiology, 2008; 48: 35-40.

[26] Iranzo, M., Sain-Pardo, I., Boluda, R., Sanchez, J. and Mormeneo, S. The use of microorganisms in environmental remediation. Annals of Microbiology, 2001; 51:135-143

[27] Vischetti, C., Casucci, C. and Perucci, P. Relationship between changes of soil microbial biomass content and imazamox and benfluralin degradation. Biology and Fertility of Soils 2002; 35(1):13-17.

[28] Huang, Y., Xiao, L., Li, F. et al. Microbial degradation of pesticide residues and an emphasis on the degradation of Cypermethrin and 3-phenoxy benzoic acid: a review. Molecules, 2018; 23: 2313. Doi: 10.3390/molecules23092313.

[29] Deng, W.Q., Lin, D.R., Yao, K. et al. Characterization of a Novel $\beta$-cypermethrin-degrading Aspergillus niger, YAT strain and the biochemical degradation pathway of $\beta$-cypermethrin. Applied Microbiology and Biotechnology, 2015; 99: 8187-8198.

[30] Joutey, N.T., Bahafid, W., Sayel, H. and Ghachtouli, N.E. Biodegradation: involved microorganisms and genetically engineered microorganisms. IntechOpen Chapter 11, 2013. http://dx.doi.org/10.5772/56194.

[31] ERD: Environmental Response Division. Fundamental principles of bioremediation (An aid to the development of bioremediation proposals). 1998

[32] Van der Heul, R.M. Environmental degradation of petroleum hydrocarbons. Utrecht University / IRAS, 3061655, November, 2009.

[33] Cases, I. and de Lorenzo, V. Genetically modified organisms for the environment: stories of success and failure and what we have learned from them. International Microbiology, 2005; 8: 213-222.

[34] Li, C.H., Wong, Y.S. and Tam, N.F. Anaerobic biodegradation of polycyclic aromatic hydrocarbons with amendment of iron (III) in mangrove sediment slurry. Bioresource Technology, 2010; 101: 8083-8092.

[35] Shan, H.F., Kurtz, H.D. and Freedman, D.L. Evaluation of strategies for anaerobic bioremediatidon of high concentrations of halomethanes. Water Research, 2010; 44: $1317-1328$.

[36] Chen, M., Shih, K., Hu, M. et al. Biostimulation of indigenous microbial communities for anaerobic transformation of pentachlorophenol in paddy soils of southern China. Journal of Agricultural and Food
Chemistry, 2012; 60: 2967-2975.

[37] Chen, B.Y., Chen, W.M. and Chang, J.S. Optimal biostimulation strategy for phenol degradation with indigenous Rhizobium ralstonia taiwanensis. Journal of Hazardous Materials, 2007; 139: 232-237.

[38] Liliane, R.R., Meneghetti, A.T., Fernando, S., Pedro, D.M. and Gabriel, C. Natural attenuation and biostimulation of biodiesel contaminated soils from Southern Brazil with different particle sizes. Journal of Environmental Science and Engineering, 2012: 155-162.

[39] Frederic, C., Emilien, P., Lenaick, G and Daniel, D. Effects of nutrient and temperature on degradation of petroleum hydrocarbons in contaminated sub-Antarctic soil. Chemosphere, 2005; 58: 1439 - 1448.

[40] Okolo, J.C., Amadi, E.N. and Odu, C.T.I. Effects of soil treatments containing poultry manure on crude oil degradation in a sandy loam soil. Applied Ecology and Environmental Research, 2005; 3: 47-53.

[41] Chaillan, F., Chayneau, C.H., Point, V., Saliot, A. and Oudot, J. Factors inhibiting bioremediation of soil contaminated with weathered oils and drill cuttings. Environmental Pollution, 2006; 144: 255-265.

[42] Abioye, O.P. Biological Remediation of Hydrocarbon and Heavy Metals Contaminated Soil, Soil Contamination, 2011; 7: 127-142.

[43] Lendvay, J.M., Loffler, F.E., Dollhopf, M. et al. Bioreactive barriers: a comparison of bioaugmentation and biostimulation for chlorinated solvent remediation. Environmental Science and Technology, 2003; 37: 1422-1431.

[44] Silva, E., Fialho, A.M., Sa-Correia, I., Burns, R.G. and Shaw, L.J. Combined bioaugmenntation and biostimilation to clean up soil contaminated with high concentrations of atrazine. Environmental Science and Technology, 2004; 38 : 632-637.

[45] Mrozik, A. and Piotrowska-Seget, Z. Bioaugmentation as a strategy for cleaning up of soils contaminated with aromatic compounds. Microbial Research, 2009 doi:10.1016/j.micres.2009.08.001.

[46] Abatenh, E., Gizaw, B., Tsegaye, Z. and Wassie, M. Application of microorganisms in bioremediation-review. Journal of Environmental Microbiology, 2017; 1(1): 02-09.

[47] Sayler, G.S. and Ripp, S. Field applications of genetically engineered microorganisms for bioremediation processes. Current Opinion in Biotechnology, 2000; 11: 286-289.

[48] Markandey, D.K. and Rajvaidya, N. Environmental Biotechnology, (1st edn.), APH Publishing Corporation, 2004: 79.

[49] Wackett, L.P. Stable isotope probing in biodegradation research. Trends in Biotechnology, 2004; 22: 153-154. 